\title{
EN EL NOMBRE DE LA REINA: \\ LA IMAGEN DE ISABEL II DURANTE LA GUERRA DE ÁFRICA (1859-1860) ${ }^{1}$
}

\section{IN THE NAME OF THE QUEEN: THE IMAGE OF ISABELLE II DURING THE HISPANO- MOROCCAN WAR (1859-1860)}

\author{
Esther Collado Fernández \\ Universidad de Alicante
}

\begin{abstract}
SUMARIO: I. LA NECESIDAD DE "HACER PATRIA".- II. UNA CRUZADA INVENTADA PARA UNA MONARQUÍA POR (RE)INVENTAR: LA ALARGADA SOMBRA DE ISABEL LA CATÓLICA.- III. EL OTRO CAMPO DE BATALLA: PRENSA, ARTE Y RITUALES MONÁRQUICOS.- IV. CONCLUSIONES.
\end{abstract}

\begin{abstract}
Resumen: La Guerra de África (1859-1860) supuso una oportunidad para afianzar el modelo liberal en todos los ámbitos de poder tras la turbulenta experiencia de las guerras carlistas y las repetidas crisis politicas de principios del siglo XIX en España. Es por ello por lo que fue aprovechada desde la monarquía para su propio fortalecimiento a través de la recuperación de viejos mitos religiosos y rituales políticos.

Este trabajo pretende analizar el papel simbólico que Isabel II tuvo en la guerra africana mediante la prensa, los discursos o los rituales que salpicaron el desarrollo de la contienda para determinar en qué medida se llevó a cabo un robustecimiento de la institución monárquica como referente simbólico y nacionalizador a través de la creación intencionada de un discurso sobre el destino inconcluso de la nación española.
\end{abstract}

\begin{abstract}
The Hispano-Moroccan War (1859-1860) was an opportunity to reinforce the liberal model in all areas of power after the troubled experience of Carlist Wars and the repeated political crises at the $19^{\text {th }}$ century in Spain. Monarchy took advantage to them in order to strengthen itself through the recovery of old religious myths and political rituals.

This work aims to analyse the symbolic role that Isabella II had at the HispanoMoroccan War through the press, speeches or rituals produced at the same time that development of the battles. This would determine to what extent and reinforcement was carried out of the monarchical institution as a symbolic and nationalizing reference based on the intentional creation of a discourse about the unfinished destiny of the Spanish nation.
\end{abstract}

1 La autora de este trabajo cuenta actualmente con una Ayuda para la formación del profesorado universitario (FPU) concedida en la convocatoria de 2014 por el Ministerio de Educación, Cultura y Deporte del Gobierno de España. Además, este trabajo forma parte de los resultados del proyecto de investigación Las monarquías en Europa meridional (siglos XIX y XX). Culturas y prácticas de la realeza (HAR2016-75954-P) financiado por el Ministerio de Economía y Competitividad y fondos FEDER. 
Palabras clave: Isabel II, monarquía, nacionalismo, Guerra de África, Reconquista.

Key words: Isabella II, monarchy, nationalism, Hispano-Moroccan War, Reconquista.

\section{LA NECESIDAD DE "HACER PATRIA"}

"Si no inventa O’Donnell la guerra de África, sabe Dios lo que habría pasado"

Benito Pérez Galdós Aita Tettauen. Episodios Nacionales IV

E1 22 de octubre de 1859 las Cortes españolas aprobaban de manera unánime la declaración de guerra al sultanato marroquí, escudándose en la negativa de este a satisfacer las reparaciones exigidas por España debido a los incidentes que había protagonizado la cábila de Anghera contra los fuertes de Ceuta durante los dias 12 y 23 del mismo mes. Estos ataques fueron declarados un ultraje al "honor nacional" que solamente podia ser resarcido mediante la fuerza, aun cuando las agresiones a los pabellones y fortificaciones españolas no eran ni novedosas, ni de una intensidad mayor de lo acostumbrado, sino que más bien podian contarse entre otros tantos enfrentamientos similares producidos durante los años 1848-1850, 1854-56 y $1857^{2}$.

Bajo este romántico pretexto, el gabinete que presidía Leopoldo O’Donnell fue enardeciendo el ardor patriótico mediante un discurso orientalista y maniqueo, en el cual la religión católica, el afán civilizador, el peso de la tradición histórica y la oportunidad de demostrar la fuerza de España ante las potencias europeas se entremezclaron para sostener una guerra que contó a su favor con la mayor parte de la opinión popular. Dejando a un lado las posibles ventajas territoriales y comerciales, su vocación principal era ocultar la cacofonía en la que se había convertido la politica española en la que las conspiraciones estaban a la orden del día y los gabinetes se sucedían con celeridad. O al menos así fue entendido por sus coetáneos:

"ide qué inapreciable valor fue la impresión que en nosotros, los españoles, causó aquel glorioso suceso [La guerra de África]! ¡Por vez primera, los hombres que perteneciamos a dos o tres distintas y sucesivas generaciones, sentíamos latir al unísono nuestros corazones, agitados por el mismo deseo, alentados por la misma esperanza, conmovidos por la misma alegría y por el mismo orgullo! ¡Por vez primera vimos alzarse vencedoras y destilando sangre nuestras espadas, sin que el triunfo arrancase lágrimas de rencor y desesperación a un hermano vencido, sin que aquella

2 Emilio de Diego García, "Intervenciones en el exterior", en Miguel Artola (coord.), Historia militar de España IV. Edad Contemporánea I, El siglo XIX, Ministerio de Defensa, Madrid, 2015, pp. 338-339. 
sangre viniese a amargar el triunfo del vencedor cayendo sobre su alma y acusándole de fratricida!"3.

En el mismo sentido se ha enfocado la historiografia más actual, defendiendo que Leopoldo O'Donnell y la Unión Liberal "inventaron" —utilizando las palabras de Benito Pérez Galdós que encabezan este trabajo-y/o aprovecharon una serie de grandilocuentes y lejanas campañas exteriores que, más allá de ambigua cuestión de la "reparación del honor nacional", tenían objetivos mucho más terrenales, centrados en solventar o al menos enterrar los problemas interiores, restaurar la confianza nacional en el Ejército y recuperar su estatus entre las naciones europeas ${ }^{4}$. La hipótesis de este trabajo se centra precisamente en el análisis de la utilidad que tuvo la guerra para la política interior del país, sin querer por ello menospreciar otros impactos económicos, sociales, o políticos que pudiera tener, para ahondar de esta manera en qué medida fue aprovechada no solo para ser parte de la propaganda gubernamental sino si lo fue también, o no, para apuntalar otro de los pilares fundamentales del sistema liberal como lo era la monarquía de Isabel II, la cual se había visto fuertemente cuestionada en los años previos tanto por el carlismo, que siguió atacándola durante todo su reinado, como por los progresistas y ciertos sectores moderados durante la revolución de $1854^{5}$.

Para la fecha que nos ocupa, la nacionalización del territorio español se encontraba en sus primeras fases. Sin querer olvidarnos de la importante obra del primer liberalismo, centrada en torno a la simbología de la Guerra de Independencia y sus relatos, podemos apuntar que tanto la retórica nacionalista como el propio estado liberal continuaban buscando fortalecer su arraigo. Pero no era tarea sencilla superar de las viejas cargas que habían heredado del Antiguo Régimen ni tampoco el descrédito que habian producido en la sociedad todas las tramas de corruptelas, pronunciamientos y fulgurantes cambios gubernamentales de la primera mitad del siglo. Despertar el sentimiento de unidad nacional no solo era útil para conseguir un mayor número de alistamientos en el ejército y facilitar imposición de nuevas cargas fiscales que sufragasen los gastos de la aventura militar, sino también para construir la base de la legitimidad liberal, monárquica y un Estado-nación moderno, aunque fuese de forma colateral ${ }^{6}$. Es por ello por lo que, en la hazaña africana, la nación y la monarquía encontraron sus destinos inevitablemente unidos. Y como tal fue

3 Ángel Maria Dacarrte, " $41^{a}$ conferencia. El Duque de Tetuán. La revolución de 1854", en Ateneo Científico, Literario y Artístico de Madrid, La España del siglo XIX. Colección de conferencias históricas celebradas durante el curso de 1885-86, Tomo III, Librería de Don Antonio San Martín, Madrid 1886, pp. 581- 651.

\footnotetext{
${ }_{4}^{4}$ Para este tema es imprescindible el trabajo de Juan Antonio Inarejos Muñoz, Intervenciones coloniales y nacionalismo español: la politica exterior de la Unión Liberal y sus vínculos con la Francia de Napoleón III (1856-1868), Sílex, Madrid, 2010.

5 Isabel Burdiel, "La ilusión monárquica del liberalismo isabelino: notas para un estudio", en Alda Blanco y Guy Thomson (coords.), Visiones del liberalismo: politica, identidad y cultura en la España del siglo XIX, Universidad de Valencia, València, 2008, pp. 137-158.

6 José Álvarez Junco, Mater dolorosa: la idea de España en el siglo XIX, Taurus, Madrid, 2001, p. 504.
} 
defendido en el Congreso: “(...) los triunfos que allí se conquisten [En África] son los triunfos de la España entera, son los triunfos de la Monarquía constitucional"7.

Hacia octubre de 1859 la Unión Liberal apenas contaba un año en el poder. Nadie entonces podia presagiar que el gabinete rompería con el baile continuo de ministros y presidentes en que se habia convertido el ejecutivo durante el reinado isabelino, permaneciendo en el poder casi cinco años seguidos. En realidad, por aquel entonces, no eran pocas las voces que en susurros en las tertulias privadas y los cafés conspiraban en su contra. De ello era informado Ramón María Narváez por su protegido el diputado José Gutiérrez de la Vega que ya en el mes de mayo hablaba de la agonía del ministerio O’Donnell, por la ineptitud á los ojos de la Reina para afrontar los peligros de la actualidad"8. De este modo, en la correspondencia de muchas de las personalidades contemporáneas durante los meses previos al conflicto africano se repetiría constantemente la preocupación o la esperanza ${ }^{9}$ - por la crisis ministerial que algunos insistieron en afirmar como prólogo a la inevitable caída del gabinete. De tales turbulencias no escapaba la figura de la reina, siendo Isabel II juez y parte en el asunto tal como sugieren las palabras del embajador francés a su gobierno al hablar de ellas:

\begin{abstract}
"Ce sont toujours les mêmes causes dissolvantes: l'abscence de tout sentiment vraiment patriotique chez les chefs de parti, leur avidité du pouvoir poussé à un degré qui les fait regarder leurs rivaux comme des ennemis mortels, et, enfin, une Reine qui est encore ce qu'elle était il y a dix ans, qu'aucune expérience n'a instruite, qui ne comprend pas que déjà plusieurs fois elle a mis sa couronne en péril, dont le coeur est bon, dit-on, mais dont les passions la mettent nécessairement à la merci d'une camarilla, qui connait trop bien tous les cotés faibles de la souveraine pour ne pas en profiter" 10 .
\end{abstract}

Como podemos extraer de la anterior correspondencia, en los meses inmediatamente anteriores al estallido del conflicto africano, el sistema español se encontraba debilitado por un problema doble: por un lado, un gobierno acosado por las conspiraciones del que solo se esperaba el momento de su caída.

7 Pedro Calvo Asensio en el Congreso de los Diputados, Diario de Sesiones del Congreso, Serie Histórica, Legislatura 1858-1860, 22-10-1859, no 148 (de 4121 a 4144), p. 4126.

8 Carta de José Gutiérrez de la Vega al Exmo. Sr. Duque de Valencia (Madrid 27 de mayo de 1859), Real Academia de la Historia, Narváez II, 9/8105, Vol. 38, 7.

${ }^{9}$ Carta de José Gutiérrez de la Vega al Exmo sr. Duque de Valencia (Madrid 8 de junio de 1859), Real Academia de la Historia, Narváez II, 9/8105, Vol. 38, 7. José Gutiérrez de la Vega expresa su convencimiento que el futuro gabinete Narváez no se haga de esperar más allá del otoño gracias a la caída del ministerio anterior.

10 "Son siempre las mismas causas nocivas: la ausencia de todo sentimiento verdaderamente patriótico entre los líderes de partido, su avidez de poder empujada a tal grado que les hace ver a sus rivales como enemigos mortales, y, finalmente una Reina que todavía es como hace diez años, de ninguna experiencia ha aprendido, que no comprende que ya varias veces ha puesto en peligro su corona, cuya corazón es bueno dicen, pero cuyas pasiones la ponen necesariamente a merced de una camarilla que conoce demasiado bien todos los puntos débiles de la soberana para no aprovecharlos". Traducción propia. Despacho de Monsieur Barrot, embajador francés en Madrid, al Conde Colonna Walewski, Ministro de Asuntos Extranjeros (Madrid, 25 de junio de 1859), Archives Diplomatiques, Correspondance politique, Espagne, vol. 853, pp. 188-193. 
Por el otro, una reina en la que no se podia confiar, una niña en manos de su camarilla sin verdadera capacidad para ejercer su papel de forma autónoma. A pesar de que el descanso estival hizo que en octubre la calma pareciese haber vuelto a la política, no pudo olvidarse lo que no se había resuelto. Quizá precisamente por la tranquilidad que parecía respirarse fue entonces cuando debió de parecerle al Consejo de Ministros que no había mejor ocasión para llevar a cabo una empresa con la que demostrar las renovadas fuerzas del gabinete y prolongar la tímida estabilidad conseguida, afianzando, a su vez, el régimen y la figura de la monarca, intrinsecamente unidos. Es esta una de las primeras características que deben ser señaladas acerca de la construcción de la imagen de Isabel II durante los acontecimientos que nos ocupan: que no fue motivada por la Casa Real en busca de una renovación, sino que es el gobierno de O’Donnell el que planifica y promueve el nuevo discurso, si bien, como analizaremos más adelante, se trata de una retroalimentación en la que la corona aprovecha esta situación para llevar a cabo sus propias acciones y rituales legitimadores.

En pleno siglo XIX, el nacionalismo se presenta en Europa como la herramienta más eficaz para apuntalar los nacientes regímenes liberales. Conocedora de ello, la Unión Liberal, se lanzó a la búsqueda del enemigo común que permitiese, por oposición, el refuerzo de la unidad nacional. La carencia de amenazas fronterizas debido a la propia situación geográfica de la península y la poca importancia que para entonces se le otorgaba al proyecto de la Unión Ibérica $^{11}$ hicieron que la elegida para la confrontación fuese la cuestión africana, anhelo de Leopoldo O'Donnell desde tiempo atrás si atendemos a Inarejos ${ }^{12}$. Las razones para lanzar la ofensiva en 1859 eran claras. En el contexto de los ataques de las cábilas a las posesiones españolas, el casus belli era incuestionable, a lo que había que añadir la ventaja desde la que se partía al enfrentarse a un Marruecos debilitado por la agonía de su sultán, que acabaría falleciendo el 9 de septiembre ${ }^{13}$. Unido a todo ello se encontraba el temor latente al expansionismo francés. Tras Argelia, Francia podría decidir continuar su camino en el norte de África, poniendo en peligro el control estratégico del Estrecho de Gibraltar ${ }^{14}$. Existía pues la oportunidad y existía el peligro. Sobre Marruecos se conjuraba la tormenta perfecta.

11 José Álvarez Junco, "El nacionalismo español como mito movilizador. Cuatro guerras", en Rafael Cruz y Manuel Pérez Ledesma (eds.), Cultura y movilización en la España contemporánea, Alianza Universidad, Madrid, 1997, pp. 35-68.

12 Juan Inarejos Muñoz, "La campaña de África de la Unión Liberal. ¿una Crimea española?”, L'Atelier $\mathrm{du}$ Centre de recherches historiques, 3 enero de 2009, en linea: http://journals.openedition.org/acrh/1805 [Última consulta 31/01/2019].

13Jerónimo Becker, España y Marruecos: sus relaciones diplomáticas durante el siglo XIX, Raoul Peant, Madrid, 1903, pp. 51-52.

14 Gonzalo Álvarez Chillida y Eloy Martín Corrales, "Haciendo patria en África. España en Marruecos y en el Golfo de Guinea”, en Javier Moreno Luzón y Xosé M. Núñez Seixas, Ser españoles, imaginarios nacionalistas en el siglo XX, RBA, Barcelona, 2013, p. 401. 


\section{UNA CRUZADA INVENTADA PARA UNA MONARQUÍA POR (RE)INVENTAR: LA ALARGADA SOMBRA DE ISABEL LA CATÓLICA}

Que la declaración de guerra contra Marruecos fuese acogida con "una unanimidad no vista siquiera en la guerra de la Independencia"15 es un indicador de que la estrategia fue exitosa, al menos al principio de la contienda. Gran parte de su triunfo fue debido a la maquinaria propagandística, que, dirigida desde el gobierno a través de la prensa, empezó a funcionar desde el primer día. Sus argumentos giraron principalmente en torno a dos cuestiones estrechamente relacionadas: la religión y el enemigo que había deshonrado a la nación, ideas que fueron calando también en otras manifestaciones e ideologias que supieron adaptarlas a su propio universo y código. Es por ello por lo que en el estudio de la propaganda relacionada con la guerra de África se puede observar que no existió una única vía desde la que entender el sentimiento nacional "herido", tal y como ha sugerido Álvarez Junco ${ }^{16}$. La utilización de la religión y el enemigo ancestral es especialmente fácil de detectar en las facciones más cercanas a la derecha conservadora, que remitieron en sus discursos a los antiguos mitos orientalistas de la guerra contra el infiel ${ }^{17}$. Pero no sería un recurso exclusivo de esa orientación política. La Unión liberal o el liberalismo más progresista también recogieron parte de esos postulados, si bien reformulándolos como un enfrentamiento barbarie-civilización en el mismo sentido que lo estaban haciendo ya la gran mayoria de las potencias imperialistas ${ }^{18}$. No hay que olvidar que, aunque se trata de una guerra muy ligada al pasado en sus justificaciones y en el imaginario popular, sus miras estuvieron puestas en construir un futuro para la nación, que, al menos internacionalmente, pasaba por aceptarse y ser aceptada como potencia europea colonizadora y civilizadora de pleno derecho ${ }^{19}$. De este modo, conjugando aspiraciones pasadas y deseos de futuro, se logró la confluencia de casi todo el espectro político, lo que explica la enorme popularidad de la que gozó la guerra ${ }^{20}$.

15 Carlos Navarro y Rodrigo, O’Donnell y su tiempo, op.cit, p. 163.

16José Álvarez Junco, "El nacionalismo español como mito movilizador. Cuatro guerras”, op. cit., pp. $43-45$.

17José Álvarez Junco, Mater dolorosa: la idea de España en el siglo XIX, op. cit, p. 514.

18 A este respecto son relevantes los trabajos de María Luisa Sánchez-Mejía Rodríguez, "Barbarie" y "civilización" en el discurso nacionalista de la guerra de África (1859-60)", Revista de estudios politicos, $\mathrm{n}^{\circ}$ 162, 2013, pp. 39-67 y José Antonio Inarejos Muñoz, "La prensa: sujeto y objeto de la politica exterior de la Unión Liberal”, en José Antonio Caballero López, José Miguel Delgado Idarreta y Cristina Sánchez de Piapón (coord.), Entre Olózaga y Sagasta: retórica, prensa y poder, Instituto de Estudios Riojanos, Logroño, 2011, pp. 395-404.

19 Antonio Moliner Prada, "La Guerra de África (1859-1860) y el proceso nacionalizador en Cataluña", comunicación provisional presentada al Congreso "La nación omnipresente: nuevos enfoques sobre los procesos de nacionalización en la España Contemporánea”, Santiago de Compostela, 6-7 septiembre de $2018, \quad$ p. $5 . \quad$ En línea https://nacionomnipresente.files.wordpress.com/2017/12/guerra-de-c3a1frica.pdf [Última consulta 01/02/2019].

20Xosé M. Núñez Seixas, “Nacionalismos y política exterior”, en Juan Carlos Pereira (dir.), La politica exterior de España (1800-2003), Ariel, Barcelona, 2003, pp. 200-202. 
En lo que respecta a la monarquía, los referentes utilizados para la revalorización de su papel simbólico durante la campaña fueron similares a los aducidos, lo que no resulta dificil de entender ya que su lógica responde a la misma falta de unidad nacional que se quería paliar. De este modo, y como ya ha sido señalado, la religión católica estuvo presente como motor simbólico del acontecimiento a través de la idea del enfrentamiento contra el musulmán, lo que, en el caso de la monarquía, se convirtió en su estandarte. El enfrentamiento contra los marroquíes adquirió aires de cruzada en esta vertiente. Se recuperó, a través de la nostalgia y en su versión mítica, la Edad Media y los triunfos militares del expansionismo durante el reinado de los Reyes Católicos, haciendo hincapié en los mitos que rodeaban a Al-Ándalus y América. Si nos planteamos el porqué del éxito de la llamada a África, la explicación pasa en gran medida por la importancia histórica que había tenido el territorio marroquí en el imaginario común, que, además, contó con un interés renovado en la primera mitad del siglo XIX gracias a la literatura y el arte ${ }^{21}$. No es casualidad que sea precisamente en este momento histórico cuando el concepto de "reconquista" empiece a utilizarse en la historiografia, gracias a Modesto Lafuente, haciendo que el enfrentamiento de los reinos ibéricos contra los musulmanes tomase el novedoso matiz de empresa nacional del que hasta entonces carecía ${ }^{22}$. África estaba de moda y para el nacionalismo español era un buen espejo. El otro sin el cual el nosotros carecía de entidad:

\begin{abstract}
"África, casi lo mismo que decir Marruecos para los españoles de tantas generaciones y desde luego para los de entonces, tenía resonancias míticas y legendarias en lo más profundo del subconsciente hispano. Aquel nombre, de confusas dimensiones geográficas, despertaba a este lado del Estrecho lo más fervorosos sentimientos patrióticos y, a la vez, lo mejor y lo peor de la imaginación colectiva. África, la otra África, era la sombra imprescindible de la luz española; una combinación reactiva de nuestra identidad. Y, no pocas veces, el recurso para exorcizar algunos de nuestros demonios, o distraer la atención pública de otros problemas"23.
\end{abstract}

Si para justificar la guerra contra Marruecos se buscó su equivalente en el pasado, la misma operación se repite con la figura de la reina. Para la monarquía isabelina, la recuperación de la imagen de los Reyes Católicos pasaba por la identificación inmediata entre Isabel I y la que en ese momento fuera la titular de la corona. Se retomaba así un paralelo histórico que fue explotado durante los primeros años del reinado de Isabel II tras la muerte de Fernando VII, un momento en el que el trono también se tambaleaba acosado por sus enemigos. La disputa carlista provocó el cuestionamiento de la legitimidad de la joven niña, que tuvo que ser defendida tanto por las armas como por la propaganda política. Es en este contexto en el que aparece la idea de la trasmutación de Isabel II como Isabel I, manifestándose a través de la proliferación de obras cuya protagonista es

${ }^{21}$ Gonzalo Álvarez Chillida y Eloy Martín Corrales: "Haciendo patria en África. España en Marruecos y en el Golfo de Guinea”, op. cit., pp. 401-402.

22 Ríos Saloma, Martín F., La Reconquista: una construcción historiográfica (siglos XVI al XIX), Marcial Pons, Madrid, 2011, p. 161.

23Emilio de Diego Garcia, “Intervenciones en el exterior”, op. cit., pp. 337-338. 
la reina medieval, así como otras en las que ambas mujeres aparecen juntas ${ }^{24}$. Muestra de ello es el grabado que Ramón Amérigo y Morales elabora a partir del cuadro de Vicente López titulado Isabel la Católica guiando a su nieta, la princesa Isabel, al templo de la gloria. En él la jovencísima reina es guiada por su antepasada hacía la gloria mientras ambas son flanqueadas por un león, símbolo doble de la monarquía y el pueblo, en clara alegoría del reinado que apenas está dando sus primeros pasos:

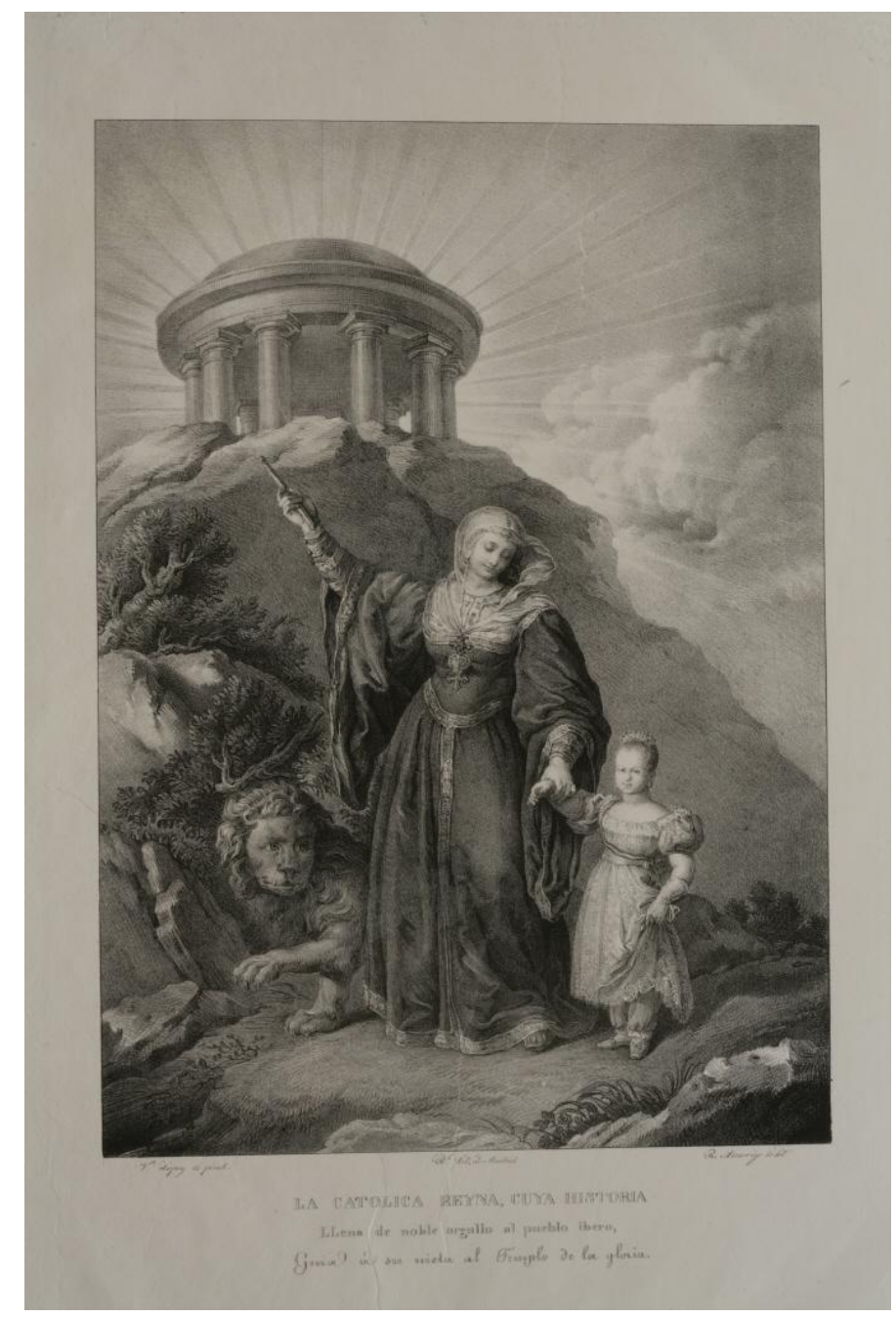

Imagen 1: Isabel la Católica guiando a su nieta, la princesa Isabel, al templo de la gloria, litografia de Ramón Amérigo y Morales, 1833. Museo del Romanticismo, CE4320. En linea:

http: / / ceres. mcu.es $/$ pages $/$ Viewer?accion $=4 \& A M u s e o=M N R \& M u s e o=M N R \& N i n v=C E$ 4320 [Última consulta: 23/02/2019]

${ }^{24} \mathrm{La}$ abundante obra pictográfica que tiene como tema el reinado de Isabel la Católica, realizada durante el reinado de Isabel II, ha sido profusamente descrita y estudiada en José Luis Díaz García, "Isabel la Católica en la pintura de historia del siglo XIX", en Gonzalo Anes y Álvarez de Castrillón y Carmen Manso Porto (coords.), Isabel la Católica y el arte, Real Academia de la Historia, Madrid, 2006, pp. 97-126. 
A mediados del siglo XIX, si bien el primer enfrentamiento con el carlismo ya había finalizado, la monarquía se encontraba debilitada una vez más. La legitimidad de Isabel II había vuelto a ser puesta en entredicho debido a la revolución de 1854 y los vaivenes del Bienio progresista, llegándose a dudar sobre la conveniencia de su continuidad como titular de la corona ${ }^{25}$. Ante este problema, la identificación Isabel I-Isabel II volvió a retomar la fuerza de los primeros años del reinado, aun cuando nunca había sido olvidada por completo.

Para este convulso momento histórico, previo al estallido de la guerra de África, encontramos la obra Paralelo entre las reinas católicas doña Isabel I y doña Isabel II, escrita en París en $1858^{26}$. En ella, el autor se recrea en la confusión entre ambas monarcas, llevando la comparación al máximo, hasta el punto de no solo hacer equivaler uno y otro reinado sino los propios hitos vitales de ambas reinas - sus nacimientos, sus matrimonios, su acceso a la corona, etc.- tal y como si una fuese casi la reencarnación de la otra. A pesar de que por simple cronología esta obra no abarca el problema de la contienda contra Marruecos, no deja de tener cierta relevancia por el parentesco de su autor que no es otro que José Güell y Renté, marido de la infanta Doña Josefa Fernanda, hermana del rey Francisco de Asís. A través de él podemos observar como el círculo de la Casa Real era consciente de la necesidad de reforzar su poder mediante la propaganda, y no solo ser un sujeto pasivo de la misma. La figura de José Güell y su obra es de esta forma un puente entre la monarquía y las ideas propuestas por la Unión Liberal, tanto más cuando es conocido que él y su mujer fueron estrechos colaboradores en las conspiraciones y la revolución de 1854, muy posiblemente continuando después unidos a los lazos que ataron el vicalvarismo ${ }^{27}$.

Avanzando en el tiempo y focalizando plenamente la atención en la Guerra de África, se puede observar que el lazo entre Isabel II y su antepasada es concebido de forma ligeramente diferente al anteriormente experimentado. Si en los retratos de los primeros años y en la obra de Güell se destacaron mayoritariamente los hitos como gobernadoras dentro de los márgenes peninsulares, en el paralelo entre ambas reinas comienza a cobrar mayor importancia el tema de la expansión territorial más allá de las fronteras. Para el nuevo relato, se parte de la base historicista de que la campaña de África, que habria formado parte de los planes de los Reyes Católicos, había quedado incompleta debido al descubrimiento de América y que la última voluntad de Isabel I de Castilla no habría sido otra que la de sus súbditos completasen la conquista. La idea completar el testamento mítico de la reina católica se convirtió en una obligación nacional que impregnó todo discurso:

"Cuando la gran Isabel, en su lecho de muerte, rogaba y mandaba a la Princesa su
hija y al Príncipe su marido, E QUE NON CESEN DE LA CONQUISTA DE AFRICA, dejó en su
testamento un objetivo que habia de deslumbrar la ambicion e todas las generaciones
españolas, en cuyo fondo palpita siempre, irreflexivo y reconcentrado, el ódio al

25 Isabel Burdiel, Isabel II. Una biografía (1830-1904), Taurus, Madrid, 2010, pp. 549-550.

26 José Güell y Renté, Paralelo entre las reinas católicas doña Isabel I y doña Isabel II, Imprenta de Jules Claye, París, 1858.

27 Luis Español Bouche, Nuevos y viejos problemas de en la sucesión de la Corona española, Ediciones Hidalguia, Madrid, 1999, pp. 67-68. 
musulman como levadura inextinguible que alli depositó la campaña de los ocho siglos. Al estallar una guerra entre España y el imperio marroquí, era de creer que fermentase esa tradicional levadura, y que el Gobierno se mostrase fuerte con la incontrastable unanimidad del sentimiento pátrio (sic)" 28.

El impacto de la teleología africana en la conciencia colectiva puede ser apreciado incluso en el nombre con el que se denominó al conflicto. Tal y como han señalado ya Álvarez Junco y otros ${ }^{29}$, no deja de ser significativo denominar con el nombre del continente a una guerra que apenas afectó más allá del área circundante a Ceuta. Esta sinécdoque geográfica es mucho más que un delirio grandilocuente del presidente del Consejo de Ministros y debe ser entendida con una clara intencionalidad propagandística: no se peleaba por un incidente menor con unas tribus rebeldes, se peleaba para cumplir los designios históricos de la nación. Y se peleaba también por la importancia del puerto de Ceuta como entrada del Mediterráneo, aunque eso se omita descaradamente. Sin embargo, al menos a nivel discursivo, se hizo ver un matiz fundamental: a diferencia de los tiempos de los Reyes Católicos en los que la expansión era entendida en el amplio sentido de la palabra, es decir, con ocupación efectiva del territorio, la expansión propuesta por el gobierno unionista se mostraba más bien vinculada a las ideas de honor. El mito del legado africano y americano de Isabel la Católica fue reformulado en la práctica puesto que Isabel II debía seguir los pasos de su antepasada, pero solo en el plano moral sin necesidad de conquista como tal. Carácter obligado, entre otras cuestiones menos abstractas, por la oposición rotunda del resto de potencias internacionales a que España llegase a dominar el Estrecho de Gibraltar, especialmente en el caso de Gran Bretaña ${ }^{30}$. Pero explicar semejante despliegue de medios solo en base a resarcir el honor nacional es caer en la vieja idea del quijotismo unionista. Hay que tener en cuenta además que la Europa que había pasado el ecuador del siglo XIX comenzó a pensar en términos colonialistas. Las viejas ideas de la patria se entremezclaron con la moderna concepción de que el progreso nacional pasaba necesariamente por incrementar la presencia exterior. Y no es el único caso. Exactamente con el mismo ánimo, se estaba llevando a cabo la expedición conjunta con Francia a la Cochinchina. Como en el tema que nos ocupa, la expedición asiática se revistió en el discurso de guerra por la religión, pero, como demuestra la correspondencia con el

28 Carlos Navarro y Rodrigo, O’Donnell y su tiempo, op., cit.,p. 162.

29 José Álvarez Junco, “El nacionalismo español como mito movilizador. Cuatro guerras”, op. cit, p. 47 .

30 Las palabras de apaciguamiento que Calderón Collantes se ve obligado a dirigirle al ministro plenipotenciario británico incluso antes de comenzar la guerra no dejan duda: "El gabinete de Madrid, como V.I. sabe, no cede en esta cuestión al impulso de un deseo preéxistente de engrandecimiento territorial; le mueve tan solo el deber sagrado de defender su dignidad y el honor de la nación". Carta del Primer Secretario de Estado español al ministro británico plenipotenciario de SA en Madrid (Palacio 6 de octubre de 1859), National Archives, Foreign Office, 185-354. 
gobierno de Napoleón III, gran parte de su importancia radicaba en realidad en la posibilidad de que España fuera aceptada como Gran potencia ${ }^{31}$.

Sin entrar a valorar si verdaderamente existió interés por la conquista territorial efectiva más allá del relato que quiso contar la propaganda gubernamental, lo que no es objeto de estas lineas, hablamos de la relectura de los mitos medievales en tanto que sus símbolos fueron reutilizados en los rituales que se desarrollaron durante la campaña. Con objeto de dotar de significado a las sucesivas batallas, se produjeron constantes referencias a sus héroes y gestas, no solo a nivel de discursivo en el parlamento y los editoriales de los periódicos afines sino dejando su huella también en el registro material. Un ejemplo bastante claro de ello lo encontramos en la espada de ceñir de lujo del General Don Leopoldo O'Donnell y Joris regalada por los reyes en conmemoración de su participación en la guerra de África que actualmente se conserva en el Museo del Ejército.

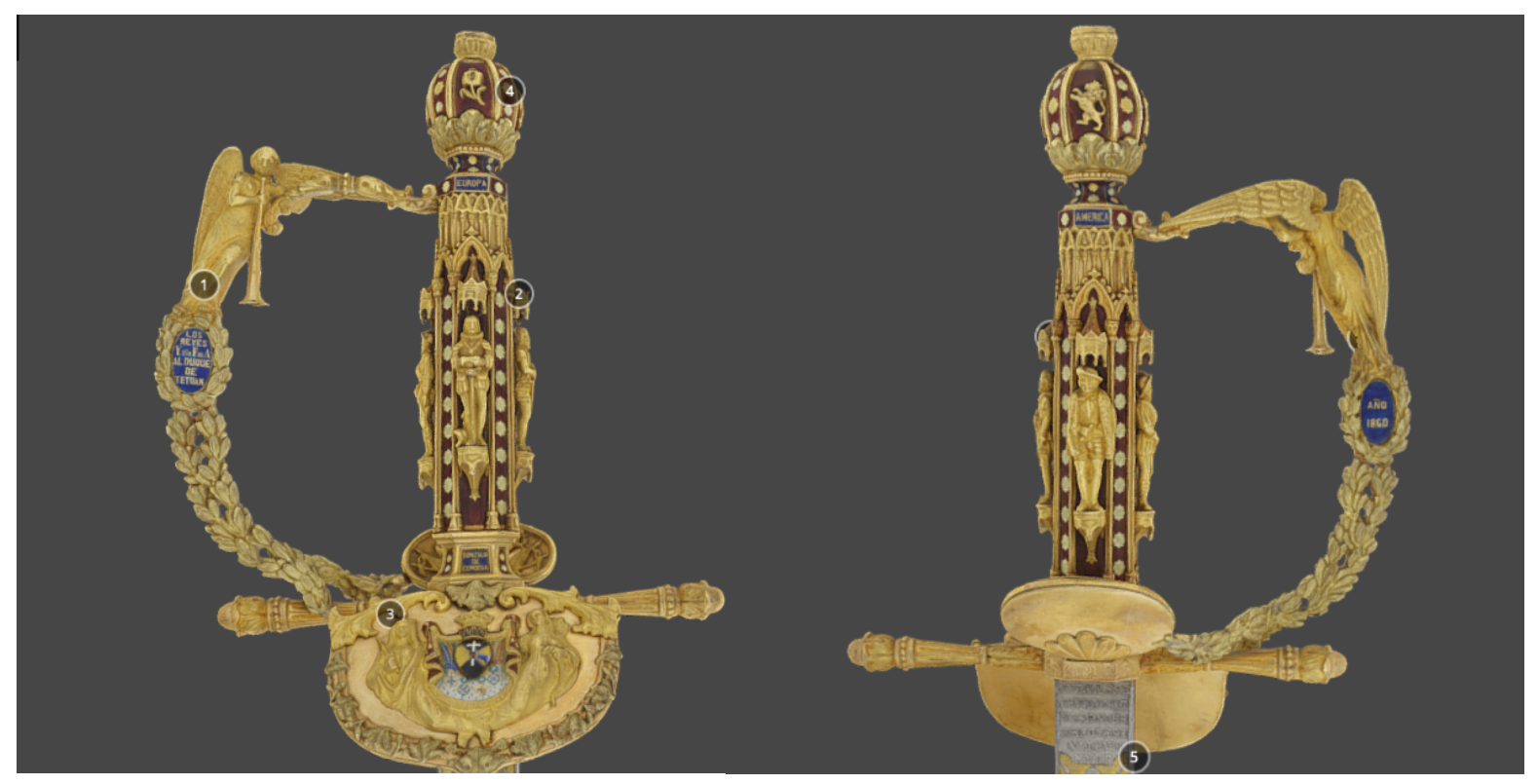

Imagen 2. Empuñadura de la espada de ceñir de lujo del General Leopoldo O'Donnell y Joris. Museo del Ejército. Captura propia. El modelo original en 3D puede ser encontrado en: http://www.museo.ejercito.es/noticias/noticias/TECNOLOGIA_DIGITAL_Y_DIFUSION_DEL_PATR IMONIO_HISTORICO.html [Última visita:13/02/2019]

Como podemos comprobar en la imagen superior, en su empuñadora se puede recorrer de un vistazo el imaginario del antiguo imperio español, invocado aquí para legitimar la guerra que acaba de concluir. En su puño, encontramos los nombres de los continentes en los que España tiene presencia durante esta época -Europa, Asia, África y América-, bajo los cuales están las estatuillas en oro de los míticos conquistadores de esos territorios - por orden Gonzalo de

31 Sara Rodicio Garcia, Una encrucijada en la historia de España: contribución hispánica a la expedición de Cochinchina, Editorial de la Universidad Complutense de Madrid. Servicio de Reprografia, Tesis doctoral 24/87, Madrid, 1987, pp. 537-573. 
Cordova, Berenguer de Entenza, Álvaro de Sande, y Hernán Cortés-. El pomo remata el conjunto añadiendo al simbolismo la flor de lis, un castillo, un león y una granada, símbolos de la monarquía, el pueblo español y la Reconquista. En una espada ornamental ninguna decoración debe entenderse como casual. Los elementos en ella reunidos responden a la intención de establecer un cordón umbilical histórico entre las batallas que libraron los generales inmortalizados y los hechos recién concluidos. En consecuencia, Leopoldo O'Donnell se convertía simbólicamente en el sucesor de aquellos grandes hombres de la patria mediante la intercesión de los nuevos Reyes Católicos, Isabell II y Francisco de Asís, que le hacian entrega del reconocimiento, diluyendo ellos mismos su identidad con los anteriores monarcas para los que en su momento trabajaron dichos héroes de la patria. Conscientemente, se resaltaba la idea de la necesidad de la institución monárquica como hilo conductor del devenir histórico y glorioso de la nación española. De hecho, la presencia de la pareja real es clara tanto a través de las ya señaladas flores de lis borbónicas que aparecen en la decoración como en la inscripción del aro del guardamano que reza: "Los reyes $\mathrm{Y} 2^{\mathrm{a}}$ y $\mathrm{F}$ de $\mathrm{A}$ al Duque de Tetuán".

\section{El OTRO CAMPO DE BATAlla: PRENSA, ARTE Y RITUALES MONÁRQUICOS}

Como venimos defendiendo a lo largo de este artículo, la Guerra de África fue también la batalla interna por conseguir la unidad nacional y la reparación de la monarquía como pilar del sistema liberal. Esta otra lucha dio lugar a una pugna paralela por las ideas y los símbolos que se habian de utilizar en esta construcción. Siguiendo la teoría de Delgado ${ }^{32}$, podemos ver durante la Guerra de África un intento de superar la antigua visión de una guerra exclusivamente por el prestigio dinástico, es decir, el valor de la contienda de cara a la monarquía y las élites para empezar a tomarse en cuenta a la opinión pública y a los intereses nacionales. Es por ello por lo que la propaganda de las distintas las imágenes se hizo principalmente a través de la prensa, y en especial por los periódicos ministeriales, en tanto que fueron la plataforma perfecta desde la que hablar y convencer a la naciente opinión pública.

Siguiendo los pasos iniciados por los británicos durante las guerras napoleónicas y la de Crimea ${ }^{33}$, los periódicos españoles hicieron de la Guerra de África la primera contienda internacional española con corresponsales de guerra enviados para narrar la crónica de las batallas de forma regular. El gobierno de

32 "La politique mise en œuvre peut être analysée sous l'angle d'une tentative pour concilier l'action extérieure des gouvernements, en grande partie encore conditionnée par une vision "archaïque" des relations internationales (intérêts dynastiques, Europe des Congrès, rôle exclusif des grands dirigeants, politique du secret), et la vision libérale et nationaliste de l'opinion publique (liberté comme valeur suprême, publicité des décisions, définition des intérêts nationaux)" . Almudena Delgado Larios, "L'union libérale et l'image de la France impériale (18561859)“, Siècles $\mathrm{n}^{\circ}$ 20, 2004, p. 31. En línea: https://journals.openedition.org/siecles/2301 [Última consulta: 20/02/2019].

33 Durante la guerra de Crimea, The Times había convertido a William Howard Russell el primer corresponsal de guerra moderno. Gaspar Núñez de Arce, Crónicas periodisticas de la guerra de África (1859-1860), Biblioteca Nueva, Madrid, 2003, p. 24. 
O’Donnell, consciente de la importancia de dar publicidad a la contienda, nombró a Carlos Navarro y Rodrigo ${ }^{34}$ cronista oficial y en calidad de ello acompañó al ejército en sus desplazamientos diarios. Pero no fue el único narrador de la contienda. Las Novedades, El Museo Universal, La Iberia y otros tantos periódicos enviaron a sus propios corresponsales y muchos de ellos se ocuparon a la vuelta de reflejar lo que habian visto en libros de enorme popularidad como es el conocidísimo caso de Pedro Antonio de Alarcón y su Diario de un testigo de la guerra de África ${ }^{35}$. Desde el punto de vista popular hubo una muy buena acogida las crónicas, llegando a agotarse los ejemplares de las jornadas más importantes e incluso a ser leídas en las calles para disfrute de aquellos sin alfabetizar ${ }^{36}$. Grabados, óleos y dibujos hicieron lo propio centrándose en retratar las batallas y los cuerpos del ejército, pero también los paisajes y los mapas de las acciones militares, llevando la exótica África a la imaginación de aquellos españoles que solamente habian oído hablar de ella. Es el caso, por ejemplo, de las ilustraciones de José Vallejo que alimentaron y completaron los reportajes periodísticos, pero también de Mariano Fortuny, enviado por la Diputación Provincial de Barcelona para tomar notas con las que retratar la gloria de los Voluntarios catalanes a su vuelta. También nos encontramos por primera vez con la fotografia de guerra, si bien su impacto directo fue menor dado que los medios técnicos no permitian su reproducción, sino que habian de copiarse en dibujo ${ }^{37}$. Respecto a las novelas y los teatros que surgieron después, hábilmente estudiados por López Barranco ${ }^{38}$, suelen centrarse bien los tópicos de odio hacia el moro mientras se fomenta la épica de los conquistadores españoles, también con una gran acogida popular.

Para lo que respecta al estudio del papel de la monarquía, esta suele quedar en un segundo plano, oculta entre las profusas descripciones de los sucesos de armas y la glorificación de la figura de algunos de los generales más populares, como Leopoldo O’Donnell o Juan Prim. La Reina, apartada del teatro de operaciones, está sin embargo presente en los gritos de ánimo durante la batalla, siendo simbólicamente el motivo último de todas las acciones y la aglutinadora de toda la tropa que se reconoce bajo una misma bandera y monarca.

En Madrid, la reina Isabel II y la corte siguieron llevando a cabo los ritos clásicos que exigía la etiqueta para evocar la participación de la corona en la contienda. Es el caso, por ejemplo, de la famosa despedida del presidente del

34 Aunque las razones de esta elección no vienen al caso, se entienden fácilmente por su puesto como periodista de La Época, y por ende su cercanía a la Unión Liberal. Es más, acabará siendo el biógrafo del mismo Leopoldo O'Donnell tras su muerte.

35 Pedro Antonio de Alarcón: Diario de un testigo de la Guerra de África, Sucesores de Reivadeneyra, Madrid, 1917.

36 Gaspar Núñez de Arce, Crónicas periodísticas de la guerra de África (1859-1860), op.cit, pp. 33-34.

37 Antonio David Palma Crespo, La Guerra de África (1859-1860) en imágenes, Universidad de Córdoba, 2016. Disponible en línea: https://helvia.uco.es/xmlui/handle/10396/13384 [Última consulta: 20/02/2019]

38 Juan José López Barranco, La guerra de Marruecos en la narrativa española (1859-1927).

Tesis doctoral, Universidad Complutense de Madrid, 2000, p. 99. Disponible en línea: http://eprints.ucm.es/4038/.[Última consulta: 20/02/2019]. 
consejo de ministros el 7 de noviembre de 1859, a partir de la cual se trazó la imagen de una Isabel deseosa de la contienda, pero también de una reina-madre que, a través de la imposición de las cruces y medallas, imploraba la protección para O’Donnell y sus súbditos:

\footnotetext{
"Ya inclina la frente el Conde;

Ya Isabel con mano trémula,

Sobre el cuello le coloca

La milagrosa cadena.

Cada cruz, cada medalla,

Es un tesoro que encierra

Una lágrima de madre

Y una bendición de Reina"39
}

Esta reina-madre de la nación mostrará también su interés en la contienda en otras ocasiones durante la misma como es el ofrecimiento de las joyas de la corona para sufragar los gastos en un gesto muy similar al que mucho más tarde tanto criticaría Castelar en su célebre artículo El Rasgo:

\begin{abstract}
"Que se tasen y vendan mis joyas si es necesario para el logro de tan santa empresa: que se disponga de mi patrimonio particular; disminuiré mi fausto; una humilde cinta brillará en mi cuello mejor que los hilos de brillantes si éstos pueden servir para defender y levantar la fama de nuestra España" 40.
\end{abstract}

\title{
IV. CONCLUSIONES
}

La Guerra de África (1859-1860) fue vista como una oportunidad para la revitalización de la imagen de la monarquía. Su discurso se basó principalmente en un nacionalismo historicista que se apoyó tanto en la religión como en la corona como agentes aglutinadores de la nación y es dentro de este contexto en el que deben ser entendidos los resultados de la contienda. Además, en su análisis debe recordarse que paralelamente y durante el resto de la duración del gabinete, la Unión Liberal estaba llevando a cabo otras muchas medidas de visibilización y acercamiento de Isabel II a su pueblo, como fueron los viajes por el territorio de las provincias españolas o las inauguraciones de las infraestructuras más recientes y modernas ${ }^{41}$.

En lo que a la propaganda monárquica atañe, durante esta campaña nos encontramos de forma predominante reutilización de la identificación entre Isabel II y su antecesora en el trono Isabel la Católica que ya había hecho su aparición

39 Eduardo Bustillo, La despedida del caudillo: romance dedicado a SS. MM. y leido por el autor en la Real Cámara en la noche del 6 de diciembre de 1859, Imprenta Aguado, Madrid, 1859. linea:

40 Texto recogido de la medalla conmemorativa conservada en el Museo del Romanticismo. En

http:/ / ceres.mcu.es / pages /Viewer?accion=4\&AMuseo=MNR\&Museo=MNR\&Ninv=CE6718 [Última consulta: 19/02/2019]

41 Rosa Ana Gutiérrez Lloret, "Isabel II, de simbolo de la libertad a deshonra de España", en Emilio La Parra López (coord.), La imagen del poder. Reyes y regentes en la España del siglo XIX, Editorial Sintesis, Madrid, 2011, p. 244-245. 
durante los primeros años de su infancia a raíz de su cuestionamiento por los carlistas. Esta identificación tiene su culmen en la campaña africana al recordarse como parte del destino inconcluso de la nación tras la Reconquista si bien se ofrece una nueva lectura de este acontecimiento, señalándose como conquista o victoria en el plano de la moral y el influjo civilizador y no como conquista efectiva del territorio como si lo fueron las campañas africanas y americanas de los Reyes Católicos a los que se evoca constantemente. Isabel II es presentada como la reencarnación de las virtudes de Isabel I pero también se actualizó en el tiempo para ofrecer una imagen de reina-madre preocupada por sus súbditos correspondiente a los valores femeninos burgueses del momento.

De lo expuesto anteriormente, entendemos que si bien la campaña monárquica fue más fuerte al principio que al final de la guerra - puesto que durante la misma quedaría eclipsada por las batallas y los generales, - , sus efectos perdurarian durante todo el reinado actuando como un fuerte refuerzo de su poder. Distintamente del revuelo que causó en la opinión popular conocer las presiones inglesas para la no colonización de Tetuán y alrededores, la monarquía se mantuvo al margen en tanto que se entendió como lo que era, una decisión meramente política.

De este modo podemos afirmar que la guerra de África pasó a engrandecer las glorias de la patria reforzando positivamente la imagen de una monarquía que todavia arrastraba las secuelas de la guerra civil, luchas entre las distintas facciones y los antojos de la camarilla, si bien el trono de Isabel II nunca terminaria de estar totalmente seguro. 